\title{
Optomagnetic Detection of MicroRNA Based on Duplex-Specific Nuclease-Assisted Target Recycling and Multilayer Core-Satellite Magnetic Superstructures
}

Tian, Bo; Ma, Jing; Qiu, Zhen; Gómez de la Torre, Teresa Zardán ; Donolato, Marco; Hansen, Mikkel Fougt; Svedlindh, Peter; Strömberg, Mattias

Published in:
A C S Nano

Link to article, DOI:

10.1021/acsnano.6b07763

Publication date:

2017

Document Version

Publisher's PDF, also known as Version of record

Link back to DTU Orbit

Citation $(A P A)$ :

Tian, B., Ma, J., Qiu, Z., Gómez de la Torre, T. Z., Donolato, M., Hansen, M. F., Svedlindh, P., \& Strömberg, M. (2017). Optomagnetic Detection of MicroRNA Based on Duplex-Specific Nuclease-Assisted Target Recycling and Multilayer Core-Satellite Magnetic Superstructures. A C S Nano, 11, 1798-1806. https://doi.org/10.1021/acsnano.6b07763

\section{General rights}

Copyright and moral rights for the publications made accessible in the public portal are retained by the authors and/or other copyright owners and it is a condition of accessing publications that users recognise and abide by the legal requirements associated with these rights.

- Users may download and print one copy of any publication from the public portal for the purpose of private study or research.

- You may not further distribute the material or use it for any profit-making activity or commercial gain

- You may freely distribute the URL identifying the publication in the public portal 


\section{Optomagnetic Detection of MicroRNA Based on Duplex-Specific Nuclease-Assisted Target Recycling and Multilayer Core-Satellite Magnetic Superstructures}

Bo Tian, ${ }^{\dagger}$ Jing Ma, Zhen Qiu, ${ }^{\dagger}$ Teresa Zardán Gómez de la Torre, ${ }^{\dagger}$ Marco Donolato, ${ }^{\S}$ Mikkel Fougt Hansen, " Peter Svedlindh, ${ }^{\dagger}$ and Mattias Strömberg*, ${ }^{\dagger}$

${ }^{\dagger}$ Department of Engineering Sciences, The Ångström Laboratory, Uppsala University, Box 534, SE-751 21 Uppsala, Sweden ${ }^{\ddagger}$ Department of Immunology, Genetics, and Pathology, The Rudbeck Laboratory, Uppsala University, SE-751 85 Uppsala, Sweden ${ }^{\S}$ BluSense Diagnostics, Fruebjergvej 3, DK-2100 Copenhagen, Denmark

"Department of Micro- and Nanotechnology, Technical University of Denmark, DTU Nanotech, Building 345B, DK-2800 Kongens Lyngby, Denmark

\section{Supporting Information}

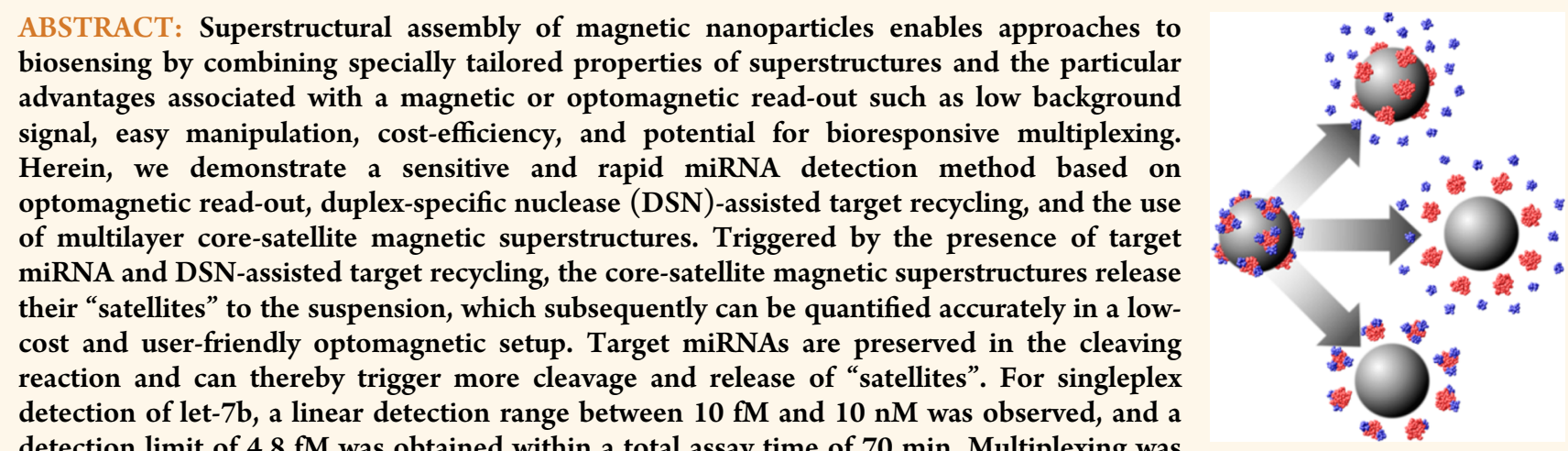
detection limit of $4.8 \mathrm{fM}$ was obtained within a total assay time of $70 \mathrm{~min}$. Multiplexing was achieved by releasing nanoparticles of different sizes in the presence of different miRNAs. The proposed method also has the advantages of single-nucleotide mismatch discrimination and the ability of quantification in a clinical sample matrix, thus holding great promise for miRNA routine multiplex diagnostics.

KEYWORDS: miRNA detection, duplex-specific nuclease, magnetic nanoparticles, core-satellite superstructures, optomagnetic bioassay

\section{I} he assembly of complex superstructures from simple building blocks is of widespread interest for engineering materials with enhanced and synergistic properties. ${ }^{1,2}$ Owing to the controllable size, molecular net charge, specific hybridization, and predictable versatile reactions with enzymes, DNA offers promising advantages in assembly and has been widely used as a scaffold, spacer, or functional polymer in nanoparticle superstructure assemblies. ${ }^{3-6}$ Among these nanoparticle superstructures assembled by DNA, "coresatellite" superstructures with a single layer or multilayers of satellite nanoparticles show great potential for imaging, drug delivery, and diagnostics. ${ }^{7-11}$ By controlling the DNA sequence as well as the composition, size, and/or surface chemistry of the nanoparticles, the "core-satellite" architectures allow us to control the dimensions and multiple functionalities of the superstructures by simply modifying the building blocks. ${ }^{8}$ In biosensing applications, magnetic particles offer advantages such as high signal stability, low background noise (in biological samples), and cost-efficiency and have therefore previously been used as building blocks of core-satellite superstructures. ${ }^{12}$ However, most of the reported magnetic core-satellite superstructures utilize magnetic particles only for manipulation and separation. ${ }^{13-15}$

MicroRNAs (miRNAs) are highly tissue-specific endogenous noncoding RNA molecules (approximately 19-23 nucleotides) with clinical applicability for profiling tumor progression and metastasis. ${ }^{16-19}$ Standard strategies for miRNA analysis include Northern blotting, ${ }^{20,21}$ quantitative reverse transcription

Received: November 17, 2016

Accepted: February 8, 2017

Published: February 8, 2017 


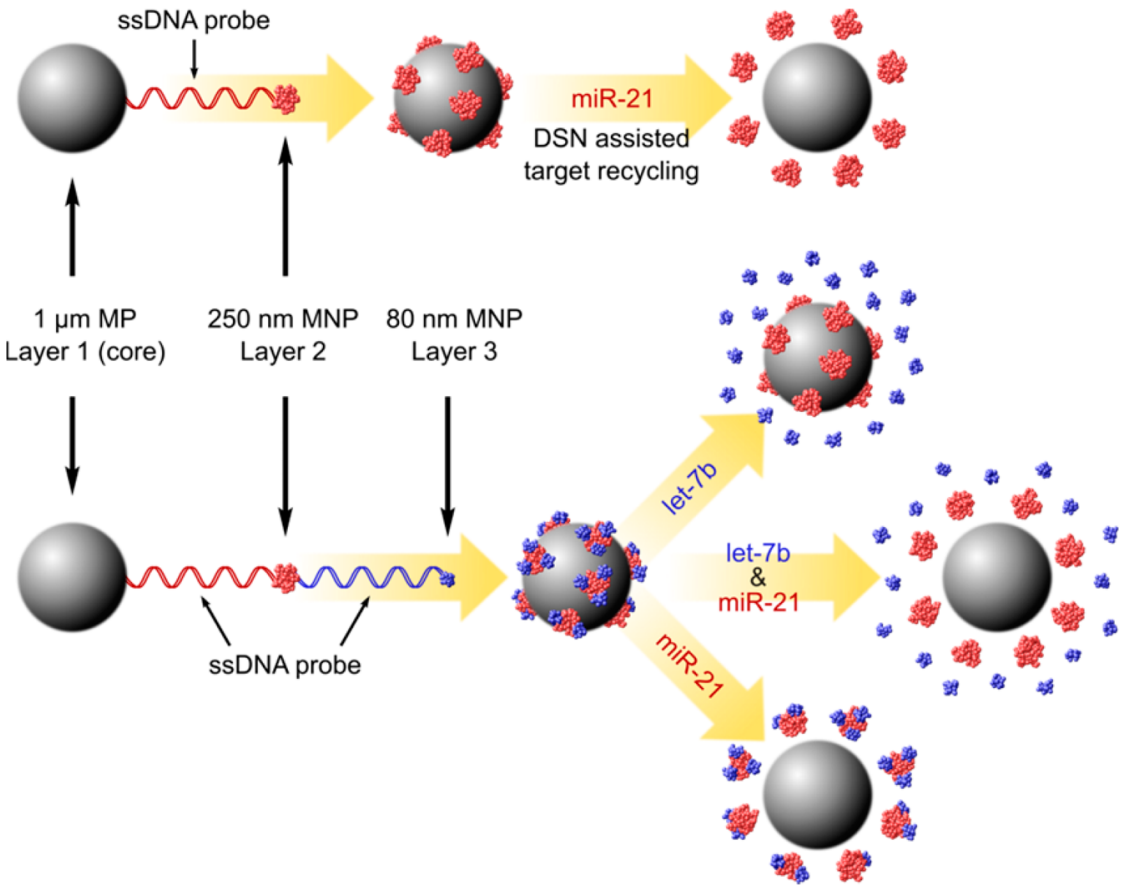

Figure 1. Schematic illustration of miRNA detection based on DSN-assisted target recycling and multilayer core-satellite magnetic superstructures. The top row shows the principle of singleplex detection based on two-layer core-satellite superstructures. The bottom row shows the principle of duplex detection based on three-layer core-satellite superstructures.

polymerase chain reaction (qRT-PCR), ${ }^{22-24}$ and oligonucleotide microarrays, ${ }^{25-27}$ which have limitations such as poor sensitivity, labor-intensive steps, requirement of high-precision thermal cycling equipment, or low specificity at the $5^{\prime}$-end of miRNA. $^{28,29}$ In recent years, duplex-specific nuclease (DSN)based isothermal biodetection methods have been developed as alternative techniques for miRNA analysis. DSN is a promising tool because of its ability to cleave DNA in DNA:RNA heteroduplexes while keeping the RNA strand intact. ${ }^{30}$ This means that the miRNA target is preserved in the cleaving reaction and can form a new heteroduplex structure which subsequently can be cleaved. This process is denoted DSNassisted target recycling, which has been employed for miRNA detection in combination with different types of biosensors such as colorimetric (visual) sensors, ${ }^{31,32}$ chemiluminescence sensors, ${ }^{33,34}$ fluorescence-based assays, ${ }^{35-38}$ surface-enhanced Raman spectroscopy-based biosensors, ${ }^{39}$ electrochemical sensors, ${ }^{40-42}$ and magnetic relaxation switch sensors. ${ }^{43}$ DSNassisted target recycling enables rapid miRNA detection using isothermal amplification, thereby decreasing the need for PCR instruments. Moreover, DSN can discriminate between perfectly and imperfectly matched short duplexes, which is crucial since miRNAs exhibit a high degree of homology between family members. ${ }^{35,42}$ In summary, DSN-based miRNA biosensors have advantages regarding sensitivity, specificity, linear detection range, assay time, and low risk of carryover contamination.

Multiplex miRNA detection can straightforwardly be conducted in optical biosensors by using labels with different spectral characteristics, but it remains challenging in magnetic biosensors. The magnetic relaxation switch sensor, reported by Lu et al., ${ }^{43}$ showed a sensitivity in the femtomolar range with a wide linear range of 5 orders of magnitude, but lacked multiplexing. DNA assembled multilayer nanoparticle superstructures provide special properties and therefore have the potential for sensitive and rapid miRNA multiplex detection. Herein, we demonstrate a miRNA detection method based on optomagnetic read-out, DSN-assisted target recycling, and coresatellite magnetic superstructures. Triggered by the presence of target miRNA and DSN-assisted target recycling, core-satellite magnetic superstructures release their "satellites" to the suspension. These "satellites" can subsequently be quantified accurately in an optomagnetic setup. The optomagnetic sensor, a rapid and low-cost volumetric magnetic nanoparticle (MNP) detection system that measures the AC magnetic excitation field-induced modulation of the optical transmission signal, provides information about the hydrodynamic size of MNPs in the suspension. First reported in 2014 by Donolato et al., ${ }^{44}$ the $405 \mathrm{~nm}$ laser-based optomagnetic sensor has been employed for the detection of several kinds of biomolecules and pathogens. $^{45-50}$ In the current work, by using magnetic superstructures with more than one layer of different MNP satellites, our biosensor enables controllable release of different satellites for multiplex detection. Below we present results for singleplex detection and demonstrate, within a total assay time of around $70 \mathrm{~min}$, a limit of detection (LOD) of $4.8 \mathrm{fM}$ with a linear detection range of approximately 6 orders of magnitude. In addition, we demonstrate the versatility of our method for duplex detection and for in vitro miRNA detection in RNA extracts from human cancer cells and miRNA spiked serum samples.

\section{RESULTS AND DISCUSSION}

Principle of the Proposed Method. The working principle of the DSN-assisted target recycling and multilayer core-satellite magnetic superstructure-based miRNA detection is illustrated in Figure 1. Target miRNAs in the suspension hybridize with the ssDNA probes located between the different layers of particles to form DNA:RNA heteroduplexes, which are the substrates for DSN and will thus be cleaved. The hydrolysis 

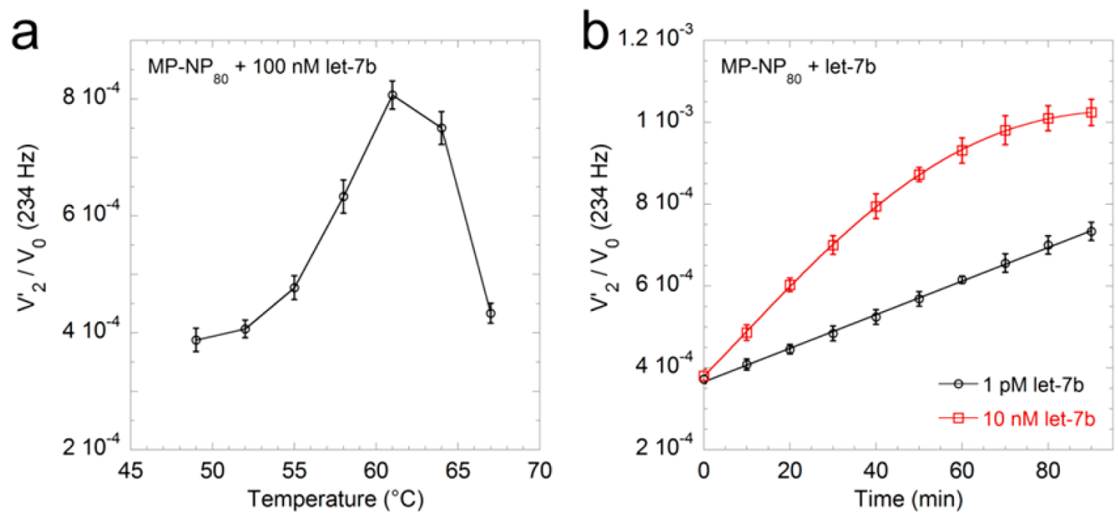

Figure 2. Effect of reaction temperature (a) and reaction time (b) on the $V_{2}{ }^{\prime} / V_{0}$ peak amplitude. A MP-NP ${ }_{80}$-based let-7b detection system was used for the optimization. Error bars indicate the standard deviation of three independent replicates.
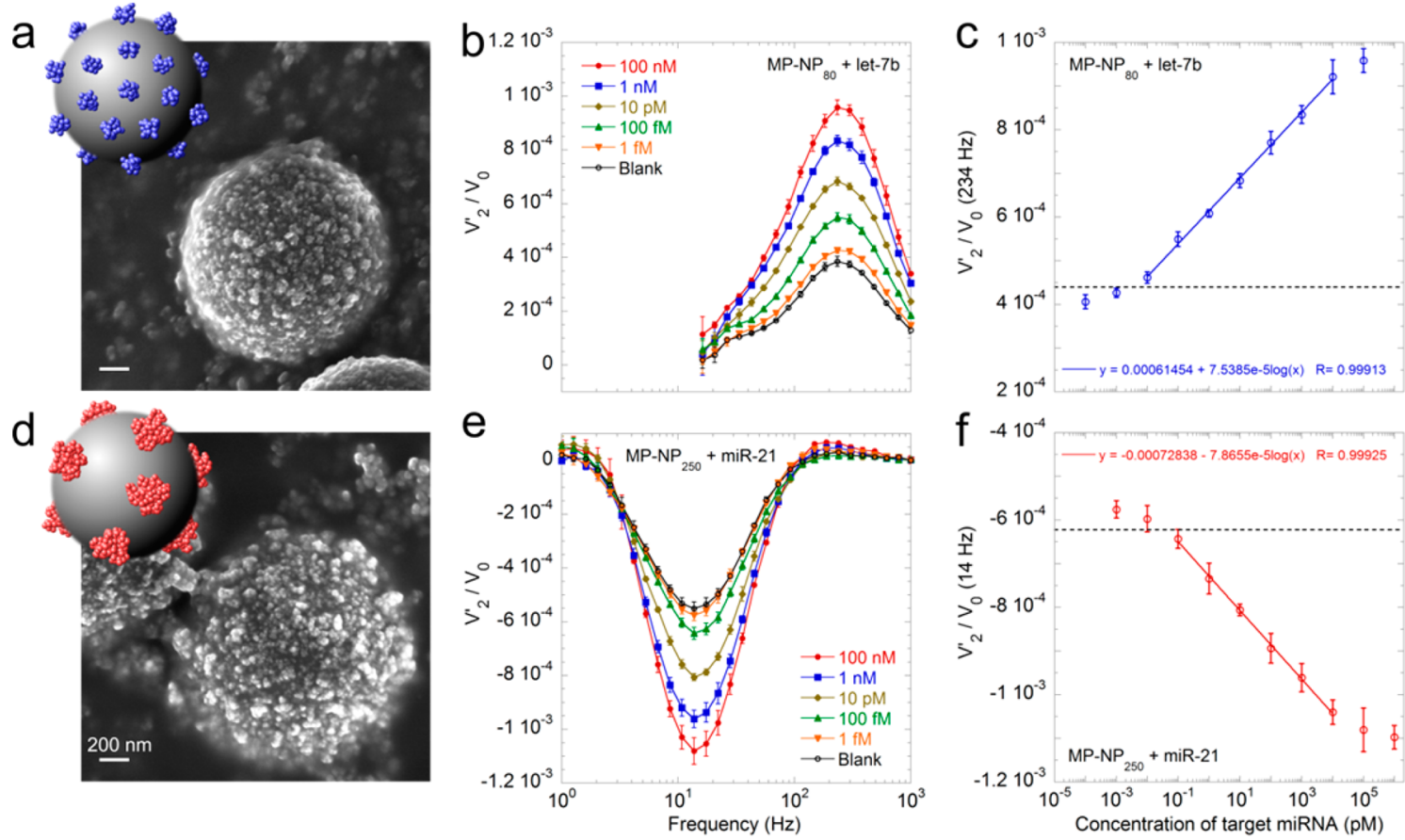

Figure 3. Representative SEM micrographs of two-layer core-satellite superstructures (a, d). $V_{2}{ }^{\prime} / V_{0}$ spectra (b, e) and dose-response curves $(c, f)$ for two-layer core-satellite superstructure-based quantitative singleplex detection of miRNA. Top (a-c) and bottom (d-f) rows show MP-NP ${ }_{80}$-based and MP-NP ${ }_{250}$-based miRNA detection, respectively. Error bars indicate the standard deviation of three independent replicates.

of ssDNA probes leads to the release of the MNPs as well as of the target miRNAs. The released miRNAs are able to bind to other ssDNA probes, thereby triggering the cleavage of more DNA:RNA heteroduplexes and the release of more MNPs. The amount of released MNPs is detected by an optomagnetic setup. For singleplex detection of miRNA, both MP-NP 80 superstructures (microparticle- $80 \mathrm{~nm}$ nanoparticle superstructures, for the detection of let-7b) and $\mathrm{MP}-\mathrm{NP}_{250}$ superstructures (microparticle-250 nm nanoparticle superstructures, for the detection of miR-21) were tested, and the working principle is shown in the top row of Figure 1. The bottom row of Figure 1 shows the principle of the duplex detection of let- $7 \mathrm{~b}$ and miR-21 using MP-NP $250-\mathrm{NP}_{80}$ superstructures (microparticle- $250 \mathrm{~nm}$ nanoparticle- $80 \mathrm{~nm}$ nanoparticle superstructures). The optomagnetic sensor records the second harmonic component of the transmitted light intensity due to a magnetic field applied at frequency $f$. In this study, we consider the in- phase second harmonic signal $V_{2}^{\prime}$ normalized by the average signal $V_{0}$. This signal displays a peak or valley, which is closely related (but not equal) to the Brownian relaxation frequency, $f_{\mathrm{B}}$, of suspended MNPs. The Brownian relaxation frequency is given by $f_{\mathrm{B}}=k_{\mathrm{B}} T /\left(6 \pi \eta V_{\mathrm{h}}\right)$, where $k_{\mathrm{B}} T$ is the thermal energy, $\eta$ is the dynamic viscosity, and $V_{\mathrm{h}}$ is the hydrodynamic volume of the relaxing entity (Supporting Information, section S1). Furthermore, the magnitude of the peak or/and valley of the $V_{2}{ }^{\prime} / V_{0}$ spectrum is proportional to the concentration of released $\mathrm{NP}_{80}$ or/and $\mathrm{NP}_{250}$. Due to the large hydrodynamic volume, MP-based superstructures cannot be detected by the optomagnetic setup since their response falls below the lower limit of the measured frequency window. Therefore, only the released MNPs contribute to the optomagnetic signal. A special phenomenon of optomagnetic measurement is the sign changes of the characteristic peaks (valleys) for MNPs of different sizes, which can be caused by the dependence of the optical 
extinction coefficient on sizes of MNPs. When the circumferences of the MNPs approach the wavelength of the light and the scattering enters the Mie regime, less light is transmitted, and the sign of the signal changes. ${ }^{51}$

Optimization of Reaction Temperature and Reaction Time. To achieve the best sensing performance for miRNA detection, the reaction temperature and reaction time were optimized using the MP-NP ${ }_{80}$-based let-7b detection system. After $30 \mathrm{~min}$ of DSN-assisted target recycling reaction at different temperatures, the MPs were separated from the sample, and the supernatant containing released MNPs was measured using the optomagnetic sensor. The $V_{2}^{\prime} / V_{0}$ peak value (at $234 \mathrm{~Hz}$ ) of $80 \mathrm{~nm} \mathrm{MNPs}$ released at different temperatures is presented in Figure 2a, from which it can be concluded that the optimum reaction temperature is around 60 ${ }^{\circ} \mathrm{C}$. The peak value decreased dramatically at temperatures higher than $60^{\circ} \mathrm{C}$, which may be attributed to denaturation of the DNA:RNA heteroduplexes. Therefore, $60{ }^{\circ} \mathrm{C}$ was chosen as the reaction temperature for the following assays. Figure $2 \mathrm{~b}$ shows the $V_{2}^{\prime} / V_{0}$ peak value as a function of reaction time. For the detection of $10 \mathrm{nM}$ of let-7b (red squares in Figure $2 \mathrm{~b}$ ), the peak value increased linearly during the first $40 \mathrm{~min}$ and reached a plateau after approximately $80 \mathrm{~min}$. For $1 \mathrm{pM}$ of let$7 \mathrm{~b}$ (black circles in Figure 2b), the $V_{2}^{\prime} / V_{0}$ peak value kept linearly increasing during the complete measurement (0-90 $\mathrm{min})$. Although the results suggested that a longer reaction time could help achieve a higher sensitivity, we chose $60 \mathrm{~min}$ for the following measurements to balance the total assay time with sensitivity. Considering that the effect of DSN concentration, another critical experimental condition, is closely related to the effect of reaction time, we did not optimize the DSN concentration but chose a concentration of $1 \mathrm{U} /$ reaction for all experiments.

Characterization of Two-Layer Core-Satellite Superstructures. Representative scanning electron microscopy (SEM) micrographs of two-layer core-satellite superstructures, MP-NP ${ }_{80}$ and MP-NP 250 , show that the MNPs are distributed uniformly over the entire surface of the MPs (Figures 3a,d and S3). By analyzing the concentration of MNPs that the two-layer superstructures can release after a complete reaction, the binding ratios between MPs and MNPs were found to be 1:90 and 1:10 for MP-NP ${ }_{80}$ and $\mathrm{MP}-\mathrm{NP}_{250}$, respectively (Supporting Information, section S2). Given an average size of $1 \mu \mathrm{m}$ for the MPs, the coverage ratios (percentage of MP surface area covered by MNPs) of $\mathrm{NP}_{80}$ and $\mathrm{NP}_{250}$ were approximately $14 \%$ and $16 \%$, respectively. The low coverage could be attributed to the irregular shape as well as the negative charge of the surfaces.

Quantitative Singleplex Detection of miRNA. Under optimized experimental conditions, the quantitative detection of target miRNA by the proposed method was investigated. Serial dilutions of let-7b, ranging from $100 \mathrm{nM}$ to $100 \mathrm{aM}$, were reacted with DSN and $\mathrm{MP}-\mathrm{NP}_{80}$, and the released MNPs were analyzed by the optomagnetic setup. The $V_{2}^{\prime} / V_{0}$ spectra are shown in Figure $3 b$, where it can be seen that the peak amplitude increases with increasing let- $7 \mathrm{~b}$ concentration. The dose-response curve of the $V_{2}^{\prime} / V_{0}$ peak amplitude $v$ s let- $7 \mathrm{~b}$ concentration is shown in Figure 3c. A linear correlation between the $V_{2}^{\prime} / V_{0}$ peak amplitude (measured at $234 \mathrm{~Hz}$ ) and logarithm of let- $7 \mathrm{~b}$ concentration was obtained between $10 \mathrm{fM}$ and $10 \mathrm{nM}$ with an average coefficient of variation $(\mathrm{CV})$ of $2.8 \%$, and an LOD of $4.8 \mathrm{fM}$ was obtained according to the $3 \sigma$ criterion. For MP-NP 250 -based miR-21 detection (Figure 3e, f), a linear correlation between the $V_{2}^{\prime} / V_{0}$ valley amplitude (measured at $14 \mathrm{~Hz}$ ) and logarithm of miR-21 concentration was obtained between $100 \mathrm{fM}$ and $10 \mathrm{nM}$ with an average CV of $3.3 \%$ and an LOD of $44.8 \mathrm{fM}$. The lower sensitivity for the miR-21 analysis could be attributed to the nonoptimum reaction temperature for $\mathrm{MP}-\mathrm{NP}_{250}$-based miR-21 detection. In addition, DNS-assisted target recycling offers a property that the sensitivity of the system can be further improved by extending the reaction time (cf. Figure 4 ). For $\mathrm{MP}-\mathrm{NP}_{80}$-based

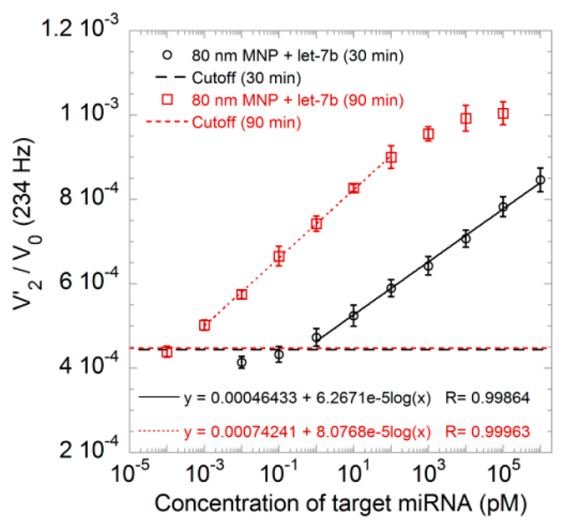

Figure 4. Relationship between $V_{2}{ }^{\prime} / V_{0}$ peak amplitude (measured at $234 \mathrm{~Hz}$ ) and logarithm of let-7b concentration for two different reaction times (30 and $90 \mathrm{~min}$ ). Error bars indicate the standard deviation of three independent replicates.

let-7b detection, a reaction time of $30 \mathrm{~min}$ led to an LOD of 0.47 pM (black circles in Figure 4), whereas a 90 min DNSassisted target recycling time provided an improved LOD of $0.22 \mathrm{fM}$ (red squares in Figure 4). Therefore, the total assay time (reaction time plus 5 min of optomagnetic measurement) can be further adjusted according to the clinical requirements on the sensitivity.

Specificity and Selectivity Evaluation. Due to the high sequence homology among miRNA family members (even single-nucleotide differences), discriminating very few mismatches is a great challenge for miRNA detection. To investigate the specificity of the proposed method, five types of miRNAs in the let-7 family were measured by the MP-NP ${ }_{80}$ based let- $7 b$ detection system. Compared with let- $7 b$, let- $7 c$ has single-nucleotide differences, let-7a has two-nucleotide differences, while let-7d and let-7e have several nucleotide differences (sequences are summarized in Table S1). All of the selected miRNAs were tested at a concentration of $1 \mathrm{nM}$. The results show that $1 \mathrm{nM}$ of let- $7 \mathrm{~b}$ exhibited the highest $V_{2}^{\prime} /$ $V_{0}$ peak amplitude, while nontargeted miRNAs produced weaker signals (cf. Figure S5). The highest nonspecific signal, produced by $1 \mathrm{nM}$ of let-7c, was found to be equal to the signal of $14 \mathrm{pM}$ let-7b (by utilizing the dose-response curve depicted in Figure 3c), implying that the proposed method is specific enough to distinguish homologous sequences with singlenucleotide differences. Moreover, miRNA mixtures containing let-7 $(0.25 \mathrm{nM}$ each of let-7a, let-7c, let-7d, and let-7e, mixed with $10 \mathrm{pM}, 0.1 \mathrm{nM}$, or $1 \mathrm{nM}$ of let-7b) were utilized to confirm the selectivity of the MP-NP ${ }_{80}$-based let- $7 \mathrm{~b}$ detection system (Figure S5). It could be concluded that $10 \mathrm{pM}$ of let-7b could be detected in a background mixture containing $0.25 \mathrm{nM}$ each of let-7a, let-7c, let-7d, and let-7e. The noticeable specificity and selectivity originates from the DSN enzyme, which can discriminate between perfectly matched DNA:RNA 

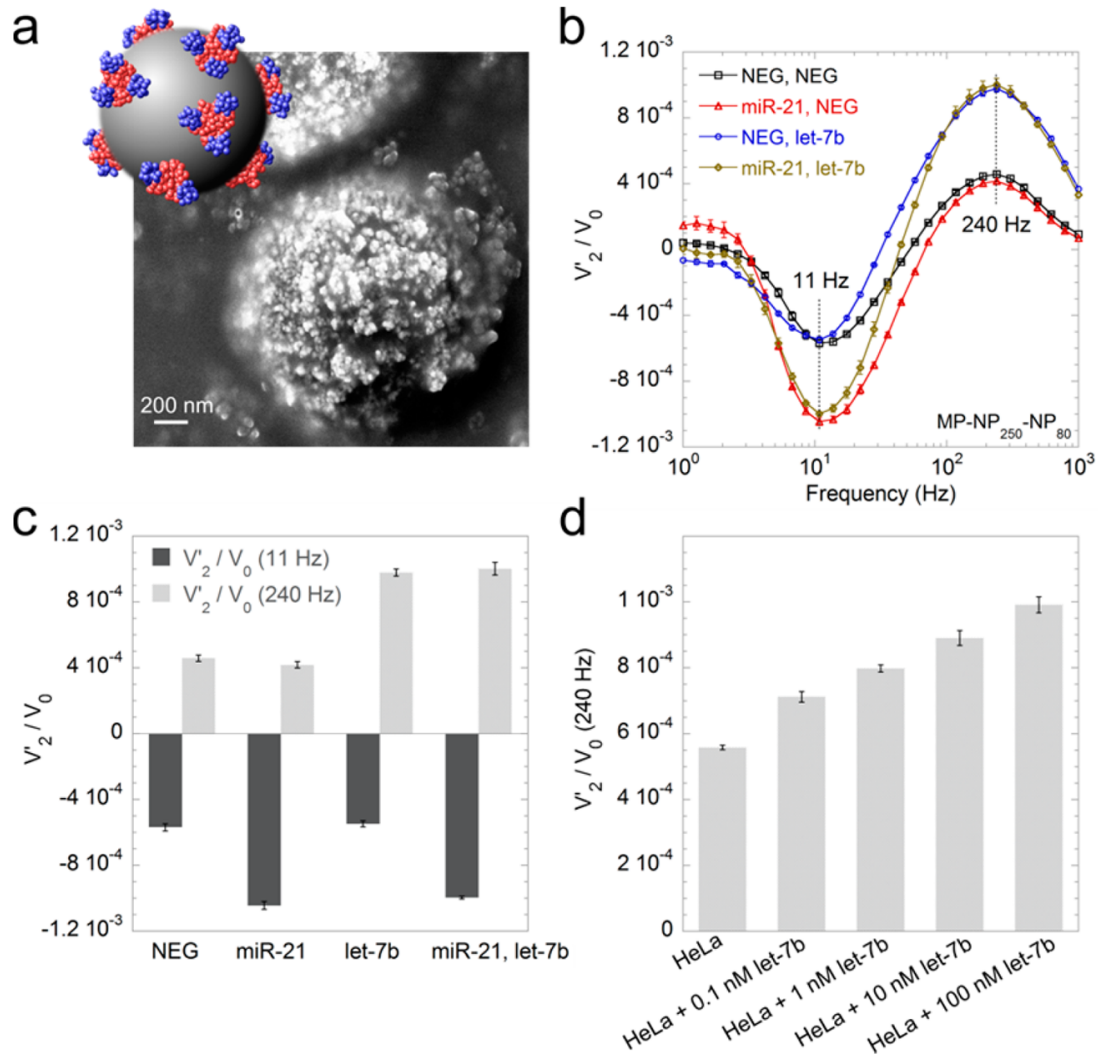

Figure 5. Duplex detection based on three-layer core-satellite superstructures. (a) Representative SEM micrograph of a three-layer coresatellite superstructure, MP-NP ${ }_{250}-\mathrm{NP}_{80}$. (b) Average $V_{2}{ }^{\prime} / V_{0}$ spectra based on three independent measurements. Two target miRNAs, namely miR-21 and let-7b, were detected simultaneously using MP-NP ${ }_{250}-\mathrm{NP}_{80}$ superstructures. The spectra are characterized by valleys/peaks located at 11 and $240 \mathrm{~Hz}$, respectively, corresponding to the released nanoparticles. NEG: absence of target miRNA (only reaction buffer). (c) The amplitude of the $V_{2}^{\prime} / V_{0}$ valleys/peaks at the frequencies of 11 and $240 \mathrm{~Hz}$. (d) $V_{2}{ }^{\prime} / V_{0}$ peak amplitude (measured at $240 \mathrm{~Hz}$ ) obtained from diluted total RNA extracts spiked with different concentrations of let-7b. Error bars indicate the standard deviation of three independent replicates.

heteroduplexes and heteroduplexes containing single-nucleotide mismatches.

Matrix Effects. The in vitro clinical applications of the miRNA detection are mainly related to the detections of cell extracts as well as serum samples. Considering that cell extracts closely resemble buffer solutions (thus, with limited matrix effects), the stability of the proposed magnetic superstructures was evaluated in diluted fetal bovine serum (FBS) samples (5\%, $10 \%, 20 \%, 40 \%$, and $80 \%$, diluted with reaction buffer, Figure S6). FBS has three main effects that may influence the assay: (1) inducing aggregation of the released nanoparticles, (2) inhibiting the DSN-based reaction, and (3) increasing the viscosity of the suspension. The aggregation effect was evaluated by measuring the $\mathrm{NP}_{80}$ directly suspended in FBS solutions. No significant nanoparticle aggregation was observed when the concentration of FBS was lower than $40 \%$ (Figure S6a). However, as seen in Figure S6b, the peak amplitudes for $\mathrm{MP}-\mathrm{NP}_{80}$-based let- $7 \mathrm{~b}$ measurements decreased due to the matrix effects of FBS (containing inhibitors, nonspecific targets, $\mathrm{RNase}$, etc.). The signal reductions of the $\mathrm{MP}-\mathrm{NP}_{80}$-based detection system were $4.3 \%, 8.5 \%, 17.1 \%$, and $34.2 \%$ when the concentrations of FBS were 10\%, 20\%, 40\%, and $80 \%$, respectively (cf. Figure S6c). In addition, a peak shift (peak position approximately equal to $f_{\mathrm{B}}=k_{\mathrm{B}} T / 6 \pi \eta V_{\mathrm{h}}$ ) could be observed, which is caused by the increased viscosity due to presence of serum. For $80 \%$ FBS samples, the characteristic peak position shifted from approximately $234 \mathrm{~Hz}$ to approximately $183 \mathrm{~Hz}$, indicating that the viscosity of FBS is approximately 1.38 times that of the reaction buffer. Since the peak amplitude was measured at $234 \mathrm{~Hz}$, the peak shift also contributed to the signal reduction, although very slightly.

Qualitative Duplex Detection of miRNA. Duplex miRNA detection was performed to demonstrate and evaluate the versatility of the three-layer core-satellite superstructures. Representative SEM micrographs of the MP-NP ${ }_{250}-\mathrm{NP}_{80}$ superstructure are shown in Figures $5 \mathrm{a}$ and S3c. By analyzing the concentration of the released MNPs after complete reaction, the binding ratio between the particles was calculated to be 1:9:72 for MP: $\mathrm{NP}_{250}: \mathrm{NP}_{80}$ (Supporting Information, section S2). The binding ratio of MP:NP ${ }_{250}(1: 9)$ in the MP$\mathrm{NP}_{250}-\mathrm{NP}_{80}$ superstructures is very close to that ratio for MP$\mathrm{NP}_{250}$ (1:10) used in the singleplex detection, suggesting that there was no obvious competition between $\mathrm{NP}_{80}$ and $\mathrm{NP}_{250}$ during the formation of the third layer of $\mathrm{NP}_{80}$ when constructing the MP-NP ${ }_{250}-\mathrm{NP}_{80}$ superstructures.

In the MP-NP $250-\mathrm{NP}_{80}$ superstructures used for duplex detection, the ssDNA probe between $\mathrm{MP}$ and $\mathrm{NP}_{250}$ was designed for the detection of miR-21, whereas the ssDNA probe between $\mathrm{NP}_{250}$ and $\mathrm{NP}_{80}$ was designed for the detection of let-7b. After the DSN-assisted target recycling reaction, the $V_{2}^{\prime} / V_{0}$ spectra of released nanoparticles were recorded. The spectrum of released $\mathrm{NP}_{250}$ as well as $\mathrm{NP}_{250}-\mathrm{NP}_{80}$ was characterized by a valley located at $11 \mathrm{~Hz}$, and the spectrum of released $\mathrm{NP}_{80}$ was characterized by a peak at $240 \mathrm{~Hz}$. The 
characteristic peak/valley positions of $\mathrm{NP}_{80}$ and $\mathrm{NP}_{250}$ in the duplex detection format were shifted a few hertz compared to the corresponding singleplex detection format, which is mainly caused by the small overlap between the spectra of the two kinds of particles. Four representative samples were analyzed, namely blank (reaction buffer), $100 \mathrm{nM}$ of let- $7 \mathrm{~b}, 100 \mathrm{nM}$ of miR-21, and a mixture containing $100 \mathrm{nM}$ of let- $7 \mathrm{~b}$ and 100 $\mathrm{nM}$ of miR-21. As depicted in Figure $5 \mathrm{~b}$, each sample has its own signature spectrum in terms of $V_{2}^{\prime} / V_{0}$ valleys/peaks. For samples containing miR-21 (red triangles and yellow diamonds), the values of $V_{2}^{\prime} / V_{0}$ at $11 \mathrm{~Hz}$ are lower than that for the blank sample (black squares). For the spectra of samples containing let- $7 \mathrm{~b}$, i.e., blue circles and yellow diamonds, the values of $V_{2}^{\prime} / V_{0}$ at $240 \mathrm{~Hz}$ are higher than that for the blank sample. The valley/peak values of the four representative samples are presented in Figure 5c. The preliminary duplex assay results of $\mathrm{MP}-\mathrm{NP}_{250}-\mathrm{NP}_{80}$-based detection system suggest that qualitative and multiplex bioassays can be achieved by utilizing multilayer core-satellite superstructures containing several layers of NPs with different hydrodynamic sizes. The qualitative duplex detection was also performed in 20\% FBS to evaluate its versatility for in vitro clinical applications (Figure S7). By comparing of Figures $5 b$ and S7, it can be observed that the performance of the duplex assay is not significantly affected by the presence of serum, i.e., the three-layer superstructures keep their stability in $20 \%$ FBS environment. Note that although the size difference between $\mathrm{NP}_{250}-\mathrm{NP}_{80}$ and $\mathrm{NP}_{250}$ cannot be observed by the current version of optomagnetic sensor, it could be achieved in future and be utilized to make logic gates for multiplex detection.

In the current duplex study, using a mixture of $\mathrm{MP}-\mathrm{NP}_{250}$ and $\mathrm{MP}-\mathrm{NP}_{80}$ superstructures can provide similar results as using $\mathrm{MP}-\mathrm{NP}_{250}-\mathrm{NP}_{80}$ (data not shown). However, the utilization of a mixture of two-layer core-satellite superstructures means a higher dose of MPs and a larger risk of aggregation, which will likely lead to considerable problems in in vivo applications because of their in vivo toxicity to liver and spleen. ${ }^{52}$

Detection of Endogenous miRNA from Human Cancer Cells. To evaluate sample matrix effects as well as demonstrate the capability of $\mathrm{MP}-\mathrm{NP}_{250}-\mathrm{NP}_{80}$ superstructures for quantitative miRNA detection in cell extracts, pure and let$7 \mathrm{~b}$ spiked total RNA extracts were detected. Total RNA extracts from human cervical cancer cells (HeLa), human breast cancer cells (MCF-7), and human lung carcinoma cells (A549) were diluted to a concentration of $50 \mu \mathrm{g} / \mathrm{mL}$ and served as the pure total RNA extracts. Synthetic let-7b was spiked into the pure total RNA extracts to prepare spiked samples of different concentrations $(0.1,1,10$, and $100 \mathrm{nM}$ of synthetic let- $7 \mathrm{~b})$. The results of the optomagnetic measurements are shown in Figure 5d (HeLa) and Figure S8 (MCF-7 and A549). By calculating the linear correlation between the $V_{2}^{\prime} / V_{0}$ peak values of the four spiked samples, the initial let- $7 \mathrm{~b}$ concentration in the total RNA extracts could be determined. A comparison between the quantification results for RNA extracts by using the proposed method and qRT-PCR is shown in Figure 6. The versatility of our assay for in vitro miRNA analysis is apparent from the good agreement between the measurement results obtained from the two different methods.

Although the proposed method has a wide linear detection range as well as a low LOD and is therefore suitable for clinical miRNA detection, the accuracy of the system needs further improvement. We ascribe the low accuracy to the unoptimized structure of core-satellite superstructures, in which the MNPs

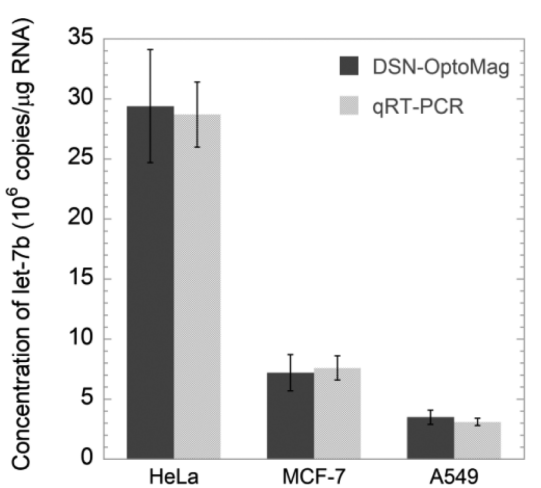

Figure 6. Quantification of let-7b in total RNA extracted from cultured cell lines. Error bars indicate the standard deviation of three independent replicates.

were linked to the core (or the inner layer) via more than one ssDNA probe. Therefore, more DSN-assisted cleavages were needed to release one MNP, leading to lower amounts of released MNPs during a certain reaction time. In an ideal situation, each MNP is linked to the core (or the inner layer) by one single ssDNA probe, and this ideal core-satellite superstructure will increase the accuracy and sensitivity of the system. Another topic in future work is increasing the MNP load on the MPs, which is also related to the accuracy as well as the relative background signal. In addition, one issue of this work is the relatively high background signal caused by the presence of unremoved MNPs after the preparation of the superstructures, which not only decreases the relative signal change from blank to positive samples but also reduces the contrast between the specific and nonspecific signals. To remove the unbound MNPs, filtration can be performed by using syringe filter units $(0.45 \mu \mathrm{m})$. The dose-response curve of the filter-treated MP-NP ${ }_{80}$-based let- $7 \mathrm{~b}$ detection system is shown in Figure S9, and the LOD is $8.4 \mathrm{fM}$. Approximately $75 \%$ of the background signal can be removed by filtration. However, although the filtration removed the unbound nanoparticles efficiently, the filter treatment was not employed in this work (except for Figure S9) since it did not significantly improve the sensitivity.

It should be emphasized that an end-point detection format was employed in this work. However, by performing the assay in a spinning microfluidic disc version of the optomagnetic system $^{46}$ with integrated temperature control, release of MNPs, removal of superstructures from the measurement volume, quantification of released MNPs, and sample resuspension can be completed within $1 \mathrm{~min}$, thereby enabling a detection format that is close to real-time. This will be a topic for future work.

\section{CONCLUSIONS}

In summary, we have presented a sensitive and rapid miRNA detection method based on optomagnetic read-out, DSNassisted target recycling and the use of multilayer core-satellite magnetic superstructures. By using $\mathrm{MP}-\mathrm{NP}_{80}$ superstructures in the proposed strategy, an LOD of $4.8 \mathrm{fM}$ with a wide linear detection range ( 6 orders of magnitude) was obtained for singleplex let-7b detection within a total assay time of $70 \mathrm{~min}$. The LOD can be further improved to subfemtomolar level by employing a longer reaction time, which is sensitive enough for miRNA detection in plasma, since the total miRNA concentration in plasma was found to be in the $100 \mathrm{fM}$ range. $^{53}$ In addition, $\mathrm{MP}-\mathrm{NP}_{250}-\mathrm{NP}_{80}$ superstructures were 
successfully employed for qualitative duplexing as well as for quantification in cell extracts. The utilization of DSN-assisted target recycling provides a simple one-step protocol eliminating the need of thermal cycling devices and has the possibility to distinguish between single-nucleotide mismatches. Consequently, benefiting from the particular advantages of a magnetic read-out and multiplexing capabilities, the utilization of multilayer core-satellite magnetic superstructures enables homogeneous and multiplex bioresponsive reactions, which are promising for diagnostics, controlled drug delivery, tissue engineering, and biomedical devices. ${ }^{54}$

\section{METHODS}

Reagents and Materials. DSN was purchased from Evrogen (Moscow, Russia) and suspended in $25 \mathrm{mM}$ Tris- $\mathrm{HCl}(\mathrm{pH} 8.0)$ and $50 \%$ glycerol. RNase inhibitor $(20 \mathrm{U} / \mu \mathrm{L})$ and Tris- $\mathrm{HCl}(1 \mathrm{M}, \mathrm{pH} 8.0)$ were purchased from Thermo Fisher Scientific (Waltham, U.S.A.). Glycerol, $\mathrm{MgCl}_{2}$, DTT, fetal bovine serum (FBS), and Millex syringe filter units $(0.45 \mu \mathrm{m})$ were purchased from Sigma-Aldrich (St. Louis, U.S.A.). The reaction buffer for the DSN-assisted target recycling was composed of $50 \mathrm{mM}$ Tris- $\mathrm{HCl}(\mathrm{pH} 8.0), 20 \mathrm{mM} \mathrm{MgCl}_{2}$, and $1 \mathrm{mM}$ DTT. MiRNA sequences (let-7a, let-7b, let-7c, let-7d, let-7e, miR-21), and ssDNA probes (biotinylated at both ends) were synthesized by Biomers (Ulm, Germany). The sequences of synthetic miRNAs and ssDNA probes are listed in Table S1. Streptavidin modified $80 \mathrm{~nm}$ MNPs $\left(1.2 \times 10^{13}\right.$ particles $/ \mathrm{mL}, 10 \mathrm{mg} / \mathrm{mL}$, product code $\left.84-19-801\right)$, streptavidin modified $250 \mathrm{~nm}$ MNPs $\left(4.9 \times 10^{11}\right.$ particles $/ \mathrm{mL}, 10 \mathrm{mg} /$ $\mathrm{mL}$, product code 09-19-252), and streptavidin modified magnetic microparticles (MPs, $5.5 \times 10^{9}$ particles $/ \mathrm{mL}, 25 \mathrm{mg} / \mathrm{mL}$, product code 08-19-203) were purchased from Micromod (Rostock, Germany). The particles used in this study were composed of small single domain particles. All the tips and tubes were RNase-free.

Assembly of Multilayer Core-Satellite Magnetic Superstructures. Tris- $\mathrm{HCl}(50 \mathrm{mM})$ buffer was used in the processes of constructing multilayer magnetic superstructure assemblies. For the synthesis of MP-NP 80 superstructures (Figures $3 a$ and S3a), streptavidin modified magnetic MPs $(100 \mu \mathrm{L}, 25 \mathrm{mg} / \mathrm{mL})$ were washed twice and resuspended in $50 \mathrm{mM}$ Tris- $\mathrm{HCl}$ buffer before conjugation. Streptavidin modified magnetic MPs $(100 \mu \mathrm{L}, 25 \mathrm{mg} /$ $\mathrm{mL})$ were mixed with $120 \mu \mathrm{L}$ of biotinylated ssDNA probe $(100 \mu \mathrm{M}$, probe for let- $7 \mathrm{~b}$ detection) and added into $780 \mu \mathrm{L}$ Tris- $\mathrm{HCl}$, followed by incubation at room temperature for $15 \mathrm{~min}$. Thereafter the probeMPs were washed twice using a magnetic separation stand in order to remove unbound ssDNA probes and resuspended in $100 \mu \mathrm{L}$ Tris-HCl. The probe-MP suspension was mixed with $100 \mu \mathrm{L}$ of streptavidin modified $80 \mathrm{~nm}$ MNPs $(10 \mathrm{mg} / \mathrm{mL})$ and $800 \mu \mathrm{L}$ Tris- $\mathrm{HCl}$, followed by incubation at room temperature for $15 \mathrm{~min}$. Unbound $80 \mathrm{~nm}$ MNPs were removed from the suspension by three times of centrifugation (2000 g, $10 \mathrm{~s}$, VWR Galaxy MiniStar Microcentrifuge). Finally, the MP-NP ${ }_{80}$ superstructures were resuspended in $200 \mu \mathrm{L}$ Tris- $\mathrm{HCl}$ and stored at $4{ }^{\circ} \mathrm{C}$. For MP-NP 250 superstructures (Figures $3 \mathrm{~d}$ and $\mathrm{S} 3 \mathrm{~b}$ ), the synthesis procedure was almost the same except for using streptavidin modified $250 \mathrm{~nm}$ MNPs and ssDNA probe for miR21 detection instead of $80 \mathrm{~nm}$ MNPs and ssDNA probe for let-7b detection.

For MP-NP $250-\mathrm{NP}_{80}$ superstructures (Figures 5a and S3c), several steps were employed to assemble the MNPs layer by layer on the MPs. MP-NP 250 superstructures $(200 \mu \mathrm{L}$, the ssDNA probes between MP and $\mathrm{NP}_{250}$ were designed for miR-21) were prepared using the protocol mentioned above and were mixed with $10 \mu \mathrm{L}$ of biotinylated ssDNA probe $(100 \mu \mathrm{M}$, probe for let- $7 \mathrm{~b}$ detection $)$ and $790 \mu \mathrm{L}$ Tris$\mathrm{HCl}$, followed by incubation at room temperature for $5 \mathrm{~min}$. Thereafter the suspension was washed twice using a magnetic separation stand to remove unbound ssDNA probes and resuspended in $100 \mu \mathrm{L}$ Tris- $\mathrm{HCl}$. After that, $20 \mu \mathrm{L}$ of streptavidin modified $80 \mathrm{~nm}$ MNPs $(10 \mathrm{mg} / \mathrm{mL})$ and $880 \mu \mathrm{L}$ Tris- $\mathrm{HCl}$ were added into the suspension followed by incubation at room temperature for $5 \mathrm{~min}$. Unbound $80 \mathrm{~nm}$ MNPs were removed by three times of centrifugation
$(2000 \mathrm{~g}, 10 \mathrm{~s})$, and finally the MP-NP${ }_{250}-\mathrm{NP}_{80}$ superstructures were resuspended in $200 \mu \mathrm{L}$ Tris- $\mathrm{HCl}$ for storage at $4{ }^{\circ} \mathrm{C}$.

Optomagnetic Measurement Setup. A detailed description of the optomagnetic setup as well as of the underlying theory is provided in Supporting Information, section S1. An AC magnetic excitation field $(2.6 \mathrm{mT})$ was applied perpendicular to the path of laser light $(\lambda=405$ $\mathrm{nm}$, light beam diameter of $2 \mathrm{~mm}$ ), and the optical path through the cuvette was $10 \mathrm{~mm}$. The in-phase component of the second harmonic component of the transmitted light intensity, $V_{2}^{\prime}$, was recorded and normalized with respect to the simultaneously measured total intensity of transmitted laser light, $V_{0}$, to compensate for the variations in laser light intensity, particle concentration, and cuvette reflection/ absorption. Due to the large hydrodynamic size, MP-based superstructures precipitate during the measurements, and the sedimentation significantly influences total intensity of transmitted laser light, $V_{0}$. Therefore, the MPs should be separated from the released MNPs before measurement. The separation was achieved either by (1) standing for $10 \mathrm{~min}$ or (2) centrifugation at $2000 \mathrm{~g}$ for $10 \mathrm{~s}$ by a mini centrifuge, and we chose the latter method in this study to reduce the total assay time. After the separation, $65 \mu \mathrm{L}$ of the released MNPs were transferred into a disposable UV-transparent cuvette (REF 67.758.001, SARSTEDT, Nümbrecht, Germany), and the cuvette was placed in the optomagnetic setup for measurement. To measure the spectra of released $80 \mathrm{~nm}$ MNPs, 20 logarithmically equidistant points were recorded in the frequency range of $10-1000 \mathrm{~Hz}$, and the data acquisition time was $150 \mathrm{~s}$. For measuring the spectra of released 250 $\mathrm{nm}$ MNPs, 30 logarithmically equidistant points were recorded in the frequency range of $1-1000 \mathrm{~Hz}$, and the data acquisition time was 240 s.

Optimization of Reaction Temperature and Reaction Time. To optimize the system for the best analytical performance, different reaction temperatures and reaction times were evaluated. For the optimization of reaction temperature, $5 \mu \mathrm{L}$ of $\mathrm{MP}^{-\mathrm{NP}_{80}}, 2.5 \mu \mathrm{L}$ of RNase inhibitor $(20 \mathrm{U} / \mu \mathrm{L}), 1 \mu \mathrm{L}$ of DSN $(1 \mathrm{U} / \mu \mathrm{L})$, and $91.5 \mu \mathrm{L}$ of $100 \mathrm{nM}$ let-7b (suspended in reaction buffer) were mixed and incubated for $30 \mathrm{~min}$ at different temperatures $(49,52,55,58,61,64$, $67{ }^{\circ} \mathrm{C}$ ). The $V_{2}^{\prime} / V_{0}$ spectra of released $80 \mathrm{~nm}$ MNPs were measured, and the $V_{2}{ }^{\prime} / V_{0}$ peak amplitude was plotted against the temperature to obtain the optimum reaction temperature. To optimize the reaction time, two concentrations of let- $7 \mathrm{~b}(1 \mathrm{pM}$ and $10 \mathrm{nM})$ were measured. Suspensions containing $5 \mu \mathrm{L}$ of MP-NP ${ }_{80}, 2.5 \mu \mathrm{L}$ of RNase inhibitor $(20 \mathrm{U} / \mu \mathrm{L}), 1 \mu \mathrm{L}$ of $\mathrm{DSN}(1 \mathrm{U} / \mu \mathrm{L})$, and $91.5 \mu \mathrm{L}$ of let- $7 \mathrm{~b}$ (concentrations of $1 \mathrm{pM}$ or $10 \mathrm{nM}$, suspended in reaction buffer) were incubated at $60{ }^{\circ} \mathrm{C}$ and measured after different reaction times. The $V_{2}^{\prime} / V_{0}$ peak amplitude of the sample was plotted against reaction time. Three independent measurements were performed for each reaction condition.

Singleplex Detection of Target miRNA. The mixture $(100 \mu \mathrm{L})$ for the let- $7 \mathrm{~b}$ detection contained $5 \mu \mathrm{L}$ of MP-NP ${ }_{80}, 2.5 \mu \mathrm{L}$ of RNase inhibitor $(20 \mathrm{U} / \mu \mathrm{L}), 1 \mu \mathrm{L}$ of DSN $(1 \mathrm{U} / \mu \mathrm{L})$, and $91.5 \mu \mathrm{L}$ of target miRNA suspended in reaction buffer (the working concentration of miRNA is $91.5 \%$ of initial concentration; the concentrations marked in the figures and used for calculation are initial concentrations). The mixture was incubated at $60{ }^{\circ} \mathrm{C}$ for $60 \mathrm{~min}$ followed by a separation step using centrifugation $(2000 \mathrm{~g}, 10 \mathrm{~s})$ in order to remove the released MNPs from the MPs. Thereafter the suspension was pipetted to a cuvette and mounted in the optomagnetic setup for measurement. The $V_{2}^{\prime} / V_{0}$ peak amplitude of the sample was plotted against the concentration of miRNA. The cutoff value was calculated as the average peak value of the blank control samples plus three standard deviations, and the LOD was obtained based on the $3 \sigma$ criterion. For the MP-NP 250 -based miR-21 detection, MP-NP ${ }_{250}$ was used instead of MP-NP ${ }_{80}$, and the cutoff value was calculated as the average peak value of the blank control samples minus three standard deviations (since the characteristic feature in the spectrum for $250 \mathrm{~nm}$ MNPs is a valley instead of a peak). Three independent measurements were performed for each concentration.

Duplex Detection of Target miRNA. Four samples (blank, 100 $\mathrm{nM}$ let-7b, $100 \mathrm{nM}$ miR-21, and a mixture containing $100 \mathrm{nM}$ let- $7 \mathrm{~b}$ and $100 \mathrm{nM} \mathrm{miR-21)}$ were characterized by DSN-assisted target 
recycling reaction and multilayer $\mathrm{MP}-\mathrm{NP}_{250}-\mathrm{NP}_{80}$ superstructures. The mixture $(100 \mu \mathrm{L})$ contained $5 \mu \mathrm{L}$ of MP-NP $250-\mathrm{NP}_{80}, 2.5 \mu \mathrm{L}$ of RNase inhibitor $(20 \mathrm{U} / \mu \mathrm{L}), 1 \mu \mathrm{L}$ of DSN $(1 \mathrm{U} / \mu \mathrm{L})$, and $91.5 \mu \mathrm{L}$ of sample. The mixture was incubated at $60{ }^{\circ} \mathrm{C}$ for $60 \mathrm{~min}$ followed by a separation step and measurement.

Specificity Test. The specificity of $\mathrm{MP}-\mathrm{NP}_{80}$-based let-7b detection was evaluated by analyzing samples containing $1 \mathrm{nM}$ of let- $7 \mathrm{a}$, let-7c, let-7d, and let-7e. In addition, microRNA mixtures containing let-7 $(0.25 \mathrm{nM}$ each of let-7a, let-7c, let-7d, and let-7e, mixed with $10 \mathrm{pM}, 0.1 \mathrm{nM}$, or $1 \mathrm{nM}$ of let- $7 \mathrm{~b}$ ) were utilized to evaluate the selectivity of the MP-NP $\mathrm{No}_{80}$-based let- $7 \mathrm{~b}$ detection system. The protocol of measurements was identical to that used in the singleplex detection. The sequences of tested miRNA are listed in Table S1.

Scanning Electron Microscopy Characterization. The morphology and nanostructure of the multilayer core-satellite superstructures $\left(\mathrm{MP}-\mathrm{NP}_{80}, \mathrm{MP}-\mathrm{NP}_{250}\right.$ and $\left.\mathrm{MP}-\mathrm{NP}_{250}-\mathrm{NP}_{80}\right)$ were characterized by scanning electron microscopy (SEM, Zeiss-1530) using an in-lens detector for secondary electrons, and the microscope was operated at $5 \mathrm{kV}$ electron beam accelerating voltage. Multilayer coresatellite superstructures were washed and resuspended in pure water before SEM imaging.

Extraction and Detection of Endogenous miRNA from Human Cancer Cells. Human cancer cell lines were cultured in Dulbecco's Modified Eagle Medium (DMEM, Gibco) supplemented with $10 \% \mathrm{FBS}$ and $100 \mathrm{IU} / \mathrm{mL}$ penicillin streptomycin. The cell lysates were prepared as follows: After harvested by trypsinization, the collected cells were washed once with phosphate-buffered saline. The cell pellet was stored at $-80{ }^{\circ} \mathrm{C}$. The total RNA of the cell pellet was purified with the RNeasy mini kit (Qiagen, Hilden, Germany). The total RNA concentration of the final supernatant was determined by using Nanodrop 1000 (Thermo Scientific). The total RNA extracts were diluted with reaction buffer to a concentration of $50 \mu \mathrm{g} / \mathrm{mL}$ and served as the pure total RNA extracts. Synthetic let-7b (target miRNA) was spiked into the pure total RNA extracts to prepare spiked samples of different concentrations $(0.1,1,10$, and $100 \mathrm{nM})$. The protocol of measurements was identical to that used in the duplex detection. The qRT-PCR quantification was performed by the Rudbeck Laboratory, Uppsala University.

\section{ASSOCIATED CONTENT}

\section{S Supporting Information}

The Supporting Information is available free of charge on the ACS Publications website at DOI: 10.1021/acsnano.6b07763.

Detailed description of the optomagnetic system and measurement principle; table of oligonucleotides used in this study; SEM images of core-satellite superstructures; determination of the binding ratios between MPs and MNPs; specificity test results; study on matrix effects; quantification of let-7b in human cancer cell line extracts; and dose-response curve of the singleplex detection based on filter-treated MP-NP ${ }_{80}(\mathrm{PDF})$

\section{AUTHOR INFORMATION}

\section{Corresponding Author}

*E-mail: mattias.stromberg@angstrom.uu.se.

ORCID ${ }^{\circ}$

Bo Tian: 0000-0002-5249-4415

Mattias Strömberg: 0000-0003-0648-3130

Notes

The authors declare no competing financial interest.

\section{ACKNOWLEDGMENTS}

This research was financially supported by Swedish Research Council Formas (project numbers 221-2012-444, 221-2014574, and 2011-1692).

\section{REFERENCES}

(1) Katz, E.; Willner, I. Integrated Nanoparticle-Biomolecule Hybrid Systems: Synthesis, Properties, and Applications. Angew. Chem., Int. Ed. 2004, 43, 6042-6108.

(2) Wang, L. B.; Xu, L. G.; Kuang, H.; Xu, C. L.; Kotov, N. A. Dynamic Nanoparticle Assemblies. Acc. Chem. Res. 2012, 45, 19161926.

(3) Alivisatos, A. P.; Johnsson, K. P.; Peng, X. G.; Wilson, T. E.; Loweth, C. J.; Bruchez, M. P.; Schultz, P. G. Organization of 'Nanocrystal Molecules' Using DNA. Nature 1996, 382, 609-611.

(4) Aldaye, F. A.; Palmer, A. L.; Sleiman, H. F. Assembling Materials with DNA as the Guide. Science 2008, 321, 1795-1799.

(5) Endo, M.; Sugiyama, H. Chemical Approaches to DNA Nanotechnology. ChemBioChem 2009, 10, 2420-2443.

(6) Torring, T.; Voigt, N. V.; Nangreave, J.; Yan, H.; Gothelf, K. V. DNA Origami: a Quantum Leap for Self-Assembly of Complex Structures. Chem. Soc. Rev. 2011, 40, 5636-5646.

(7) Sebba, D. S.; Mock, J. J.; Smith, D. R.; LaBean, T. H.; Lazarides, A. A. Reconfigurable Core-Satellite Nanoassemblies as MolecularlyDriven Plasmonic Switches. Nano Lett. 2008, 8, 1803-1808.

(8) Chou, L. Y.; Zagorovsky, K.; Chan, W. C. DNA Assembly of Nanoparticle Superstructures for Controlled Biological Delivery and Elimination. Nat. Nanotechnol. 2014, 9, 148-155.

(9) Zhang, T. T.; Li, H.; Hou, S. W.; Dong, Y. Q.; Pang, G. S.; Zhang, Y. W. Construction of Plasmonic Core-Satellite Nanostructures on Substrates Based on DNA-Directed Self-Assembly as a Sensitive and Reproducible Biosensor. ACS Appl. Mater. Interfaces 2015, 7, 2713127139.

(10) Sun, M.; Xu, L.; Ma, W.; Wu, X.; Kuang, H.; Wang, L.; Xu, C. Hierarchical Plasmonic Nanorods and Upconversion Core-Satellite Nanoassemblies for Multimodal Imaging-Guided Combination Phototherapy. Adv. Mater. 2016, 28, 898-904.

(11) Zhao, X. L.; Xu, L. G.; Sun, M. Z.; Ma, W.; Wu, X. L.; Kuang, H.; Wang, L. B.; Xu, C. L. Gold-Quantum Dot Core-Satellite Assemblies for Lighting Up MicroRNA In Vitro and In Vivo. Small 2016, 12, 4662-4668.

(12) Lee, H.; Shin, T. H.; Cheon, J.; Weissleder, R. Recent Developments in Magnetic Diagnostic Systems. Chem. Rev. 2015, 115, 10690-10724.

(13) Ge, J. P.; Zhang, Q.; Zhang, T. R.; Yin, Y. D. Core-Satellite Nanocomposite Catalysts Protected by a Porous Silica Shell: Controllable Reactivity, High Stability, and Magnetic Recyclability. Angew. Chem., Int. Ed. 2008, 47, 8924-8928.

(14) Zhang, M.; He, X. W.; Chen, L. X.; Zhang, Y. K. Preparation of IDA-Cu Functionalized Core-Satellite $\mathrm{Fe} 3 \mathrm{O} 4 /$ Polydopamine/Au Magnetic Nanocomposites and Their Application for Depletion of Abundant Protein in Bovine Blood. J. Mater. Chem. 2010, 20, 1069610704.

(15) Sun, Z.; Du, J.; Yan, L.; Chen, S.; Yang, Z.; Jing, C. Multifunctional Fe3O4@SiO2-Au Satellite Structured SERS Probe for Charge Selective Detection of Food Dyes. ACS Appl. Mater. Interfaces 2016, 8, 3056-3062.

(16) Lu, J.; Getz, G.; Miska, E. A.; Alvarez-Saavedra, E.; Lamb, J.; Peck, D.; Sweet-Cordero, A.; Ebert, B. L.; Mak, R. H.; Ferrando, A. A.; Downing, J. R.; Jacks, T.; Horvitz, H. R.; Golub, T. R. MicroRNA Expression Profiles Classify Human Cancers. Nature 2005, 435, 834838.

(17) Calin, G. A.; Croce, C. M. MicroRNA Signatures in Human Cancers. Nat. Rev. Cancer 2006, 6, 857-866.

(18) Esquela-Kerscher, A.; Slack, F. J. Oncomirs-MicroRNAs with a Role in Cancer. Nat. Rev. Cancer 2006, 6, 259-269.

(19) Inui, M.; Martello, G.; Piccolo, S. MicroRNA Control of Signal Transduction. Nat. Rev. Mol. Cell Biol. 2010, 11, 252-263.

(20) Lagos-Quintana, M.; Rauhut, R.; Lendeckel, W.; Tuschl, T. Identification of Novel Genes Coding for Small Expressed RNAs. Science 2001, 294, 853-858.

(21) Valoczi, A.; Hornyik, C.; Varga, N.; Burgyan, J.; Kauppinen, S.; Havelda, Z. Sensitive and Specific Detection of MicroRNAs by 
Northern Blot Analysis Using LNA-Modified Oligonucleotide Probes. Nucleic Acids Res. 2004, 32, e175.

(22) Chen, C.; Ridzon, D. A.; Broomer, A. J.; Zhou, Z.; Lee, D. H.; Nguyen, J. T.; Barbisin, M.; Xu, N. L.; Mahuvakar, V. R.; Andersen, M. R.; Lao, K. Q.; Livak, K. J.; Guegler, K. J. Real-Time Quantification of MicroRNAs by Stem-Loop RT-PCR. Nucleic Acids Res. 2005, 33, e179.

(23) Benes, V.; Castoldi, M. Expression Profiling of MicroRNA Using Real-Time Quantitative PCR, How to Use It and What Is Available. Methods 2010, 50, 244-249.

(24) Redshaw, N.; Wilkes, T.; Whale, A.; Cowen, S.; Huggett, J.; Foy, C. A. A Comparison of MiRNA Isolation and RT-qPCR Technologies and Their Effects on Quantification Accuracy and Repeatability. BioTechniques 2013, 54, 155-164.

(25) Barad, O.; Meiri, E.; Avniel, A.; Aharonov, R.; Barzilai, A.; Bentwich, I.; Einav, U.; Gilad, S.; Hurban, P.; Karov, Y.; Lobenhofer, E. K.; Sharon, E.; Shiboleth, Y. M.; Shtutman, M.; Bentwich, Z.; Einat, P. MicroRNA Expression Detected by Oligonucleotide Microarrays: System Establishment and Expression Profiling in Human Tissues. Genome Res. 2004, 14, 2486-2494.

(26) Thomson, J. M.; Parker, J.; Perou, C. M.; Hammond, S. M. A Custom Microarray Platform for Analysis of MicroRNA Gene Expression. Nat. Methods 2004, 1, 47-53.

(27) Li, W.; Ruan, K. MicroRNA Detection by Microarray. Anal. Bioanal. Chem. 2009, 394, 1117-1124.

(28) Baker, M. MicroRNA Profiling: Separating Signal from Noise. Nat. Methods 2010, 7, 687-692.

(29) Shen, Y. T.; Tian, F.; Chen, Z. Z.; Li, R.; Ge, Q. Y.; Lu, Z. H. Amplification-Based Method for MicroRNA Detection. Biosens. Bioelectron. 2015, 71, 322-331.

(30) Qiu, X.; Zhang, H.; Yu, H.; Jiang, T.; Luo, Y. Duplex-Specific Nuclease-Mediated Bioanalysis. Trends Biotechnol. 2015, 33, 180-188.

(31) Deng, H. M.; Shen, W.; Ren, Y. Q.; Gao, Z. Q. A Highly Sensitive and Selective Homogenous Assay for Profiling MicroRNA Expression. Biosens. Bioelectron. 2014, 54, 650-655.

(32) Zhou, Y. Y.; Zhang, J. Y.; Zhao, L. K.; Li, Y. C.; Chen, H.; Li, S. L.; Cheng, Y. Q. Visual Detection of Multiplex MicroRNAs Using Cationic Conjugated Polymer Materials. ACS Appl. Mater. Interfaces 2016, 8, 1520-1526.

(33) Feng, Q. M.; Shen, Y. Z.; Li, M. X.; Zhang, Z. L.; Zhao, W.; Xu, J. J.; Chen, H. Y. Dual-Wavelength Electrochemiluminescence Ratiometry Based on Resonance Energy Transfer between Au Nanoparticles Functionalized g-C3N4 Nanosheet and $\mathrm{Ru}$ (bpy) (3) (2+) for MicroRNA Detection. Anal. Chem. 2016, 88, 937-944.

(34) Wang, Q.; Yin, B. C.; Ye, B. C. A Novel Polydopamine-Based Chemiluminescence Resonance Energy Transfer Method for MicroRNA Detection Coupling Duplex-Specific Nuclease-Aided Target Recycling Strategy. Biosens. Bioelectron. 2016, 80, 366-372.

(35) Yin, B. C.; Liu, Y. Q.; Ye, B. C. One-Step, Multiplexed Fluorescence Detection of MicroRNAs Based on Duplex-Specific Nuclease Signal Amplification. J. Am. Chem. Soc. 2012, 134, 50645067.

(36) Degliangeli, F.; Kshirsagar, P.; Brunetti, V.; Pompa, P. P.; Fiammengo, R. Absolute and Direct MicroRNA Quantification Using DNA-Gold Nanoparticle Probes. J. Am. Chem. Soc. 2014, 136, 22642267.

(37) Xi, Q.; Zhou, D. M.; Kan, Y. Y.; Ge, J.; Wu, Z. K.; Yu, R. Q.; Jiang, J. H. Highly Sensitive and Selective Strategy for MicroRNA Detection Based on WS2 Nanosheet Mediated Fluorescence Quenching and Duplex-Specific Nuclease Signal Amplification. Anal. Chem. 2014, 86, 1361-1365.

(38) Lv, W. F.; Zhao, J. M.; Situ, B.; Li, B.; Ma, W.; Liu, J. M.; Wu, Z. X.; Wang, W.; Yan, X. H.; Zheng, L. A Target-Triggered Dual Amplification Strategy for Sensitive Detection of MicroRNA. Biosens. Bioelectron. 2016, 83, 250-255.

(39) Pang, Y. F.; Wang, C. W.; Wang, J.; Sun, Z. W.; Xiao, R.; Wang, S. Q. Fe3O4@Ag Magnetic Nanoparticles for MicroRNA Capture and Duplex-Specific Nuclease Signal Amplification Based SERS Detection in Cancer Cells. Biosens. Bioelectron. 2016, 79, 574-580.
(40) Yang, C. Y.; Dou, B. T.; Shi, K.; Chai, Y. Q.; Xiang, Y.; Yuan, R. Multiplexed and Amplified Electronic Sensor for the Detection of MicroRNAs from Cancer Cells. Anal. Chem. 2014, 86, 11913-11918.

(41) Hao, N.; Dai, P. P.; Yu, T.; Xu, J. J.; Chen, H. Y. A Dual TargetRecycling Amplification Strategy for Sensitive Detection of MicroRNAs Based on Duplex-Specific Nuclease and Catalytic Hairpin Assembly. Chem. Commun. 2015, 51, 13504-13507.

(42) Zhang, J.; Wu, D. Z.; Cai, S. X.; Chen, M.; Xia, Y. K.; Wu, F.; Chen, J. H. An Immobilization-Free Electrochemical Impedance Biosensor Based on Duplex-Specific Nuclease Assisted Target Recycling for Amplified Detection of MicroRNA. Biosens. Bioelectron. 2016, 75, 452-457.

(43) Lu, W. J.; Chen, Y. P.; Liu, Z.; Tang, W. B.; Feng, Q.; Sun, J. S.; Jiang, X. Y. Quantitative Detection of MicroRNA in One Step via Next Generation Magnetic Relaxation Switch Sensing. ACS Nano 2016, 10, 6685-6692.

(44) Donolato, M.; Antunes, P.; Bejhed, R. S.; Zardán Gómez de la Torre, T.; Østerberg, F. W.; Strömberg, M.; Nilsson, M.; Strømme, M.; Svedlindh, P.; Hansen, M. F.; Vavassori, P. Novel Readout Method for Molecular Diagnostic Assays Based on Optical Measurements of Magnetic Nanobead Dynamics. Anal. Chem. 2015, 87, 1622-1629.

(45) Antunes, P.; Watterson, D.; Parmvi, M.; Burger, R.; Boisen, A.; Young, P.; Cooper, M. A.; Hansen, M. F.; Ranzoni, A.; Donolato, M. Quantification of NS1 Dengue Biomarker in Serum via Optomagnetic Nanocluster Detection. Sci. Rep. 2015, 5, 16145.

(46) Donolato, M.; Antunes, P.; Zardán Gómez de la Torre, T.; Hwu, E. T.; Chen, C. H.; Burger, R.; Rizzi, G.; Bosco, F. G.; Strømme, M.; Boisen, A.; Hansen, M. F. Quantification of Rolling Circle Amplified DNA Using Magnetic Nanobeads and a Blu-ray Optical Pick-up Unit. Biosens. Bioelectron. 2015, 67, 649-655.

(47) Mezger, A.; Fock, J.; Antunes, P.; Østerberg, F. W.; Boisen, A.; Nilsson, M.; Hansen, M. F.; Ahlford, A.; Donolato, M. Scalable DNABased Magnetic Nanoparticle Agglutination Assay for Bacterial Detection in Patient Samples. ACS Nano 2015, 9, 7374-7382.

(48) Tian, B.; Bejhed, R. S.; Svedlindh, P.; Strömberg, M. Blu-ray Optomagnetic Measurement Based Competitive Immunoassay for Salmonella Detection. Biosens. Bioelectron. 2016, 77, 32-39.

(49) Yang, J.; Donolato, M.; Pinto, A.; Bosco, F. G.; Hwu, E. T.; Chen, C. H.; Alstrom, T. S.; Lee, G. H.; Schafer, T.; Vavassori, P.; Boisen, A.; Lin, Q.; Hansen, M. F. Blu-ray Based Optomagnetic Aptasensor for Detection of Small Molecules. Biosens. Bioelectron. 2016, 75, 396-403.

(50) Tian, B.; Ma, J.; Zardán Gómez de la Torre, T.; Bálint, Á.; Donolato, M.; Hansen, M. F.; Svedlindh, P.; Strömberg, M. Rapid Newcastle Disease Virus Detection Based on Loop-Mediated Isothermal Amplification and Optomagnetic Readout. ACS Sensors 2016, 1, 1228-1234.

(51) Fock, J.; Parmvi, M.; Strömberg, M.; Svedlindh, P.; Donolato, M.; Hansen, M. F. Comparison of Optomagnetic and AC Susceptibility Readouts in a Magnetic Nanoparticle Agglutination Assay for Detection of C-Reactive Protein. Biosens. Bioelectron. 2017, $88,94-100$.

(52) Liu, G.; Gao, J. H.; Ai, H.; Chen, X. Y. Applications and Potential Toxicity of Magnetic Iron Oxide Nanoparticles. Small 2013, 9, 1533-1545.

(53) Williams, Z.; Ben-Dov, I. Z.; Elias, R.; Mihailovic, A.; Brown, M.; Rosenwaks, Z.; Tuschl, T. Comprehensive Profiling of Circulating MicroRNA via Small RNA Sequencing of cDNA Libraries Reveals Biomarker Potential and Limitations. Proc. Natl. Acad. Sci. U. S. A. 2013, 110, 4255-4260.

(54) Lu, Y.; Aimetti, A. A.; Langer, R.; Gu, Z. Bioresponsive Materials. Nat. Rev. Mater. 2016, 2, 16075. 